\title{
Quercetin Ameliorates Experimental Autoimmune Myocarditis in Rats
}

\author{
Milenković Marina, Arsenović-Ranin Nevena, Stojić-Vukanić Zorica, Bufan Biljana, Vučićević Dragana, Jančić Ivan \\ Department of Microbiology and Immunology, Faculty of Pharmacy, Vojvode Stepe 450, 11221 Belgrade, Serbia
}

Received, January 15, 2010; Revised, July 28, 2010; Accepted, August 27, 2010; Published, September 3, 2010

\begin{abstract}
Purpose. Experimental autoimmune myocarditis (EAM) in rats is an animal model of human giant cell myocarditis and post-myocarditis dilated cardiomyopathy. The pathogenesis of EAM has not been elucidated, but there is accumulating evidence that cytokines secreted from monocytes/macrophages and $\mathrm{T}$ cells play a crucial role in the induction and progression of disease. Flavonoids are a large group of polyphenolic compounds abundantly present in the human diet, which scavenge oxygen radicals and have anti-inflammatory activities. Having in mind in vivo beneficial effects of flavonoid quercetin in different animal models of immunoinflammatory diseases such as experimental autoimmune encephalomyelitis and adjuvant arthritis, on the one side, and its in vitro suppressive effect on production of tumor necrosis factor-alpha (TNF- $\alpha$ ), on the other side, we investigated the effects of quercetin on EAM in rats. Methods. Myocarditis was induced in Dark Agouti (DA) rats by injection of porcine cardiac myosin and quercetin at doses of 10 or $20 \mathrm{mg} / \mathrm{kg}$ was orally administered from days 0 to 21 after induction of disease. The severity of myocarditis was evaluated by determination of heart weight/body weight ratio $(\mathrm{Hw} / \mathrm{Bw})$ and histopathological examination of hearts. The levels of cytokines (TNF- $\alpha$, IL-12, IL-17 and IL-10) in serum and lymph node cells (LNC) culture supernatants were measured by ELISA. Results. The rats treated with $20 \mathrm{mg} / \mathrm{kg}$ of quercetin had significantly decreased incidence of EAM, Hw/Bw, macroscopic and microscopic scores of hearts. Further, in EAM rats treated with quercetin levels of TNF- $\alpha$ and IL-17 were significantly lower, while the level of IL-10 was significantly higher both in serum and culture supernatants of LNC stimulated with concanavalin A compared with vehicle-treated animals. Conclusions. The present study suggests that quercetin ameliorates EAM, at least in part, by interfering production of proinflammatory (TNF- $\alpha$ and IL-17) and/or anti-inflammatory (IL-10) cytokines.
\end{abstract}

\section{INTRODUCTION}

Myocarditis and its sequela, dilated cardiomyopathy (DCM), are the major causes of heart failure $(1,2)$. Myocarditis, inflammation of the heart, is defined pathologically as mononuclear or mixed cellular infiltration associated with myocyte necrosis and degeneration in the presence or absence of fibrosis (3). At present, there is no universally accepted effective therapy for myocarditis, and therapeutic strategy is mostly directed to management of symptoms and complications.

Autoimmunity has been hypothesized to play a role in the pathogenesis of human myocarditis and DCM (4), however, this issue is incompletely understood. In animal models autoimmune myocarditis/DCM can be initiated by a viral infection or by immunization with heart-specific autoantigens (5).

Rat experimental autoimmune myocarditis (EAM), an animal model of human giant cell myocarditis and DCM, may be elicited by immunization with cardiac myosin or cardiac myosin peptides. In Lewis and Dark Agouti (DA) rats EAM is characterized by severe myocardial damage with a peak of inflammation in the heart around day 21 after immunization $(6,7)$. The pathogenesis of EAM has not been elucidated, but there is compelling evidence suggesting that the cytokines secreted from both monocytes/macrophages and $\mathrm{T}$ cells are involved in the induction and resolution of EAM. Th1 type cytokines (IL-2 and IFN- $\gamma$ ) and proinflammatory cytokines (IL-1 $\beta$ and TNF- $\alpha$ ) have been detected only in the inflammatory phase, while the production of Th2 cytokines (IL-10 and TGF- $\beta$ ) has been found in the recovery phase (8). Interleukin-12 (IL-12), which is produced mainly by antigen-presenting cells and exerts potent proinflammatory effect by stimulating Th1 response, has been suggested to play a key role in development of EAM (9).

Correspondence Author: Marina Milenković, M.D., Ph.D., Department of Microbiology and Immunology, Faculty of Pharmacy, 450 Vojvode Stepe, 1221 Belgrade (Kumodraž), Serbia, E-mail: marinama@pharmacy.bg.ac.rs 
Recently, it has been reported that IL-23, rather than IL-12, is responsible for inflammatory heart disease, however, IL-23 and IL-12 have redundant activities in priming and expansion of autoreactive cells (10). IL-23 has been implicated in the development of a new population of CD4+ cells termed Th17 (11), which produce IL-17, proinflammatory cytokine that activates $\mathrm{T}$ cells and other immune cells to produce a variety of cytokines, chemokines and cell adhesion molecules (12). Th17 cells have been shown to exert a pathogenic role in the development of $\operatorname{EAM}(10,13,14)$.

Flavonoids are a large group of polyphenolic compounds abundantly present in certain vegetables, fruits, seeds and beverages (e.g. tea and wine) (15). Dietary intake rich in these compounds has been suggested to decrease the risk of cardiovascular disease and cancer (16) and reduce the incidence of cerebrovascular disease in humans (17). The beneficial effects of flavonoids, including quercetin, have been attributed to their anti-oxidant and anti-inflammatory properties. Several reports have suggested that a variety diseases associated with oxidative stress and inflammatory diseases may be beneficially influenced by flavonoids $(16,18-22)$. The antiinflammatory activity of quercetin has been reported in an animal model of arthritis (19). Interestingly, in experimental autoimmune encephalomyelitis (EAE), opposite effects of quercetin have been reported. Hendriks et al. found that quercetin suppresses EAE in rats and prevents monocyte infiltration into the CNS (23), while Verbeek et al. showed that quercetin fails to beneficially influence the course of EAE in mice, but, instead, suppresses recovery from acute inflammatory damage (22). Although the mechanisms of action and anti-inflammatory effects of quercetin are not yet fully elucidated, it has been reported that quercetin inhibits production and gene expression of TNF- $\alpha$ by human peripheral blood mononuclear cells and murine macrophages via modulation of NF- $\kappa B$ and IкB $(24,25)$. Quercetin also modulates nitric oxide metabolism in stimulated macrophages (26).

Having in mind the beneficial effects of quercetin in animal models of immunoinflammatory diseases such as EAE and adjuvant arthritis on the one side, and its in vitro suppressive effects on production of proinflammatory cytokines, on the other side, we investigated whether quercetin could ameliorate EAM in rats. To our knowledge it is for the first time that effect of quercetin on EAM has been tested.

\section{METHODS}

\section{Experimental animals and immunization}

Seven-week-old male Dark Agouti (DA) rats, weighing 190-220g, were purchased from the Military Medical Academy Animal House, Belgrade, housed in polyethylene cages containing sterilized wood shavings and given rodent chow and tap water ad libitum.

Purified porcine cardiac myosin (Sigma Chemical Co., St.Louis, MO, USA) was dissolved in $0,01 \mathrm{M}$ phosphate-buffered saline (PBS) and emulsified with an equal volume of complete Freund's adjuvant (FCA) (Difco, Sparks, MD, USA) supplemented with Mycobacterium tuberculosis H37RA (Difco) at a concentration of $10 \mathrm{mg} / \mathrm{ml}$. On days 0 and 7, rats were injected in the footpads subcutaneously with $0,1 \mathrm{ml}$ of emulsion, yielding an immunizing dose of 1,0 $\mathrm{mg} /$ body of cardiac myosin per rat $(27,28)$. Control rats were injected with PBS in FCA. No rat died prior to day 21 .

All experimental procedures and protocols conformed to institutional guidelines for the care and use of animals in research No 2/09 (Ethics Committee of the Faculty of Pharmacy, Belgrade, Serbia).

\section{Treatment with quercetin}

Effects of quercetin on EAM were evaluated using two different doses of quercetin: 10 and 20 $\mathrm{mg}$ per kilogram of body weight $(\mathrm{mg} / \mathrm{kg} \mathrm{bw})$.

Five experimental groups (A-E) were created. Groups A-C consisted of 10 rats immunized with myosin/FCA (EAM rats), groups $\mathrm{D}$ and $\mathrm{E}$ consisted of 6 rats injected with PBS in FCA (control groups). Groups A and B were treated per os during 21 days (starting from day 0 to day 20) with 10 and $20 \mathrm{mg}$ of quercetin (Sigma, St. Louis MO, USA) per kilogram of body weight, respectively. Group $\mathrm{C}$ received per os vehicle. Group D was treated with quercetin $(20 \mathrm{mg} / \mathrm{kg}$ bw) in parallel with the diseased protocol, while group E received vehicle.

\section{Histopathology}

All rats were sacrificed under ether anesthesia on day 21 after immunization. Blood samples were obtained from inferior vena cava. After thoracotomy the hearts were rinsed with saline and macroscopic findings of hearts were classified into four grades according to the 
following criteria: 0 (normal appearance), 1 (focal discolored area), 2 (multiple or diffuse discolored areas not exceeding $1 / 3$ of the heart), 3 (diffuse discolored areas not exceeding $2 / 3$ of the heart) and 4 (diffuse discolored areas exceeding $2 / 3$ of the heart). Subsequently, heart weight without atria and the body weight were measured, and the ratio of heart weight to body weight $(\mathrm{Hw} / \mathrm{Bw})$ was calculated. The heart was fixed in $10 \%$ buffered formalin, embedded in paraffin, sectioned into $4 \mu \mathrm{m}$ slices (five transverse sections per heart ) and stained with hematoxylin eosin. Two observers (one pathologist) scored the histopathological scores blindly. Microscopic findings were graded: 0 (normal), 1 (lesion extent not exceeding $1 \%$ of a transverse section), 2 (not exceeding 10\%), 3 (not exceeding 50\%), and 4 (exceeding 50\%). We measured the lesion area using a square lattice scale in an eye lens of a microscope.

\section{Cell cultures}

Lymph node cells (LNC) were harvested and single-cell suspensions were obtained by passing through a stainless steel mesh screen. Cells were suspended in RPMI 1640 (Sigma-Aldrich Chemie $\mathrm{Gmb}$ ) supplemented with $10 \%$ heat-inactivated fetal calf serum (FCS) (Gibco, Grand Island, N.Y. USA), $2 \mathrm{mM}$ L-glutamine (Serva, Heidelberg, Germany), $1 \mathrm{mM}$ sodium pyruvate (Serva), 100 units/ml penicillin (ICN, Costa Mesa, CA, USA) and $100 \mu \mathrm{g} / \mathrm{ml}$ streptomycin (ICN). Cells were seeded in 96-well plates $\left(1 \times 10^{6} / \mathrm{ml}\right.$; Nunc A/S $)$ and stimulated with $2,5 \mu \mathrm{g} / \mathrm{ml}$ of concanavalin A (ConA; Pharmacia, Sweden) for cytokine production. All cultures were run in triplicate. Cell culture supernatants were collected after $72 \mathrm{~h}$ of stimulation and were frozen until analyzed.

\section{Cytokine measurement}

On day 21 after immunization cytokines (TNF- $\alpha$, IL-12, IL-17 and IL-10) were measured in serum and culture supernatants using commerially available ELISA kits (for TNF- $\alpha$ and IL-10: Quantikine ELISA kit; R\&D Systems, Minneapolis, USA; for IL-12 (p70): BioSource International, Camarillo, CA, USA; for IL-17: Biosciences, San Diego, CA, USA) according to manufacturer's instructions. Detection limits were $5 \mathrm{pg} / \mathrm{ml}$ for TNF- $\alpha, 2 \mathrm{pg} / \mathrm{ml}$ for IL-17, 2,5 $\mathrm{pg} / \mathrm{ml}$ for IL-12 (p70) and $10 \mathrm{pg} / \mathrm{ml}$ for IL-10.

\section{Statistical Analysis}

Data are presented as mean \pm standard deviation (SD). The Mann-Whitney U test was applied using the program SPSS11.5 for Windows (SPSS, Inc., Chicago, IL) for comparison of data between groups. A p value less than 0.05 was considered significant.

\section{RESULTS}

\section{Effects of quercetin on clinical course of EAM and histological parameters}

The potential beneficial effects of quercetin on EAM were evaluated by using two doses of quercetin, 10 and $20 \mathrm{mg} / \mathrm{kg}$ bw. These doses are lower than those previously tested in animal studies $(23,29)$ and more correspond to doses used in human subjects (30). EAM animals (groups A and B) were treated per os with quercetin from day 0 to day 20 after induction of disease, and on day 21 all animals were sacrificed.

The $\mathrm{Hw} / \mathrm{Bw}$ ratio was increased in vehicletreated EAM animals (group C) compared with that in normal control group (group E). In the vehicle-treated animals hearts were markedly enlarged and contained diffuse grayish areas (mean macroscopic score $1.6 \pm 0.5$ ). Microscopically, inflammatory lesions composed of marked infiltration by mononuclear cells were observed (Table 1, Figure 1b). However, treatment with a higher dose of quercetin (20 $\mathrm{mg} / \mathrm{kg} \mathrm{bw}$, group B) suppressed the development of EAM. Myocarditis was observed in only $50 \%$ of these animals. Within this treatment group, $\mathrm{Hw} / \mathrm{Bw}$ ratio, macroscopic and microscopic scores were significantly lower in comparison with those in vehicle-treated EAM rats (Table 1).

Histological examination revealed mild inflammation consisting of sporadic inflammatory foci scattered between the muscle fibers (Figure 1c). Treatment with $10 \mathrm{mg} / \mathrm{kg}$ bw of quercetin (group A) was not effective in reducing the incidence and severity of the disease (Table 1). The ratio of the myocarditis-affected area in group A was smaller than that in vehicle-treated EAM rats (group C), however, the difference did not reach statistical significance (Table 1, Figure 1d). 


\begin{tabular}{|c|c|c|c|c|}
\hline Group & $\begin{array}{c}\text { Disease } \\
\text { incidence }(\%)\end{array}$ & $\mathrm{Hw} / \mathrm{Bw} \times 100$ & $\begin{array}{l}\text { Macroscopic } \\
\text { score }\end{array}$ & $\begin{array}{l}\text { Microscopic } \\
\text { score }\end{array}$ \\
\hline A: Myosin/FCA + quercetin $10 \mathrm{mg} / \mathrm{kg}$ (0-20 day) & $7 / 10(70)$ & $3.43 \pm 0.18$ & $1.2 \pm 0.5$ & $2.1 \pm 0.4$ \\
\hline B: Myosin/FCA + quercetin $20 \mathrm{mg} / \mathrm{kg}$ (0-20 day) & $5 / 10(50)$ & $3.23 \pm 0.23 *$ & $0.8 \pm 0.4^{* *}$ & $1.2 \pm 0.5^{* *}$ \\
\hline $\mathrm{C}: \mathrm{Myosin} / \mathrm{FCA}+$ vehicle & $9 / 10(90)$ & $3.50 \pm 0.15$ & $1.6 \pm 0.5$ & $2.4 \pm 0.5$ \\
\hline D: PBS/FCA + quercetin $20 \mathrm{mg} / \mathrm{kg}$ (0-20 day) & $0 / 6(0)$ & $3.18 \pm 0.20$ & 0 & 0 \\
\hline E: PBS/FCA & $0 / 6(0)$ & $3.00 \pm 0.30$ & 0 & 0 \\
\hline
\end{tabular}

Values are expressed as the mean \pm S.D. and are significantly different from those of the vehicle-treated EAM rats (group C). ${ }^{*} \mathrm{p}<0.05,{ }^{* *} \mathrm{p}<0.01$.

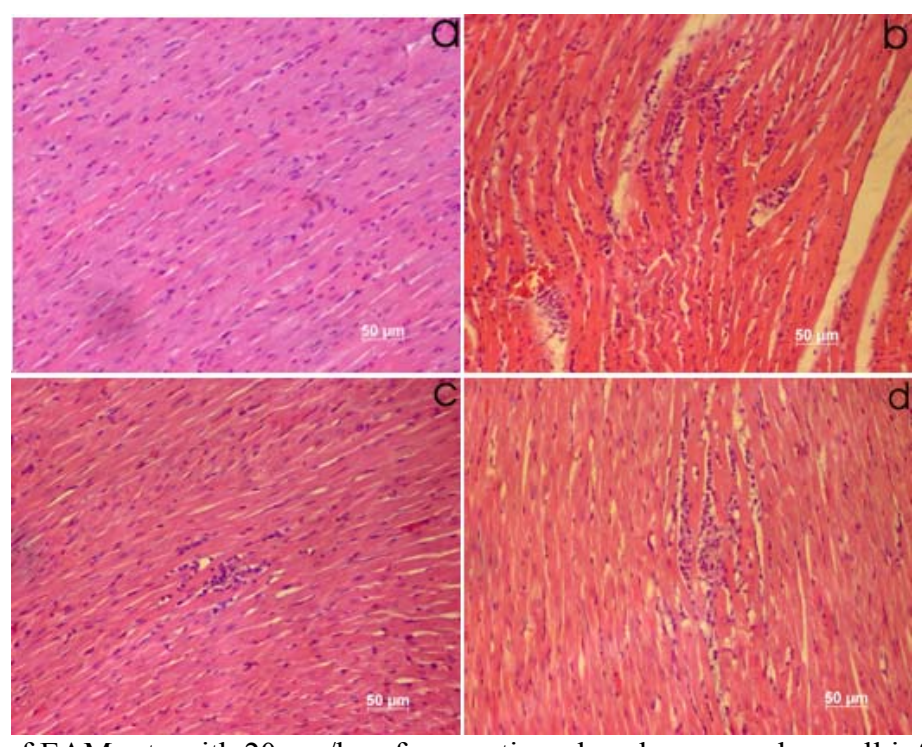

Figure 1. The treatment of EAM rats with $20 \mathrm{mg} / \mathrm{kg}$ of quercetin reduced mononuclear cell infiltration in myocardium. (a) The heart from a control animal which was injected with PBS in FCA appears normal. (b) The heart from a rat with myocarditis treated with vehicle. Inflammatory infiltrate is shown. (c) Representative histopathology of a rat with myocarditis treated from days 0 to 21 with $20 \mathrm{mg} / \mathrm{kg}$ and (d) $10 \mathrm{mg} / \mathrm{kg}$ of quercetin. Hematoxylin and eosin staining, original magnification: $\mathrm{x} 160$.

\section{Effects of quercetin on serum levels of cytokines}

To determine if quercetin treatment alters serum levels of TNF- $\alpha$, IL-12, IL-17 and IL-10, serum was isolated and then analyzed by ELISA. As shown in Figure 2, serum level of TNF- $\alpha$ was markedly decreased in EAM animals treated with $20 \mathrm{mg} / \mathrm{kg}$ bw of quercetin (group B) compared with vehicle- treated EAM rats (group C). Since in our preliminary study the serum level of IL-10 was below the limit of the sensitivity of the assay (10 pg/ml), on day 21 after immunization five animals from each group were injected i.p. with $1 \mathrm{mg} / \mathrm{kg}$ bw of lipopolysaccharide (LPS) from E.coli (serotype O55:B5, Sigma), and 4h later blood samples were collected. Injection of LPS provokes the in vivo activation of macrophages, which within 2-6h leads to a release of IL-10 into the circulation (31). Compared with the vehicletreated group, there was significant increase of the level of IL-10 in $20 \mathrm{mg} / \mathrm{kg}$ bw quercetin-treated group (Figure 2). No significant differences in the serum concentrations of IL-12 and IL-17 were observed between vehicle- and quercetin-treated EAM rats (Figure 2).

\section{Effects of quercetin on production of cytokines in the supernatants of LNC}

The levels of TNF- $\alpha$ and IL-17 in LNC culture supernatants were significantly decreased in EAM animals treated with $20 \mathrm{mg} / \mathrm{kg}$ bw of quercetin (group B) compared with vehicle-treated EAM animals (group C). However, production of IL-10 was significantly increased in both 10 and 20 $\mathrm{mg} / \mathrm{kg}$ bw quercetin-treated groups. There was no difference in concentration of IL-12 between quercetin- and vehicle-treated EAM animals (Figure 3). 


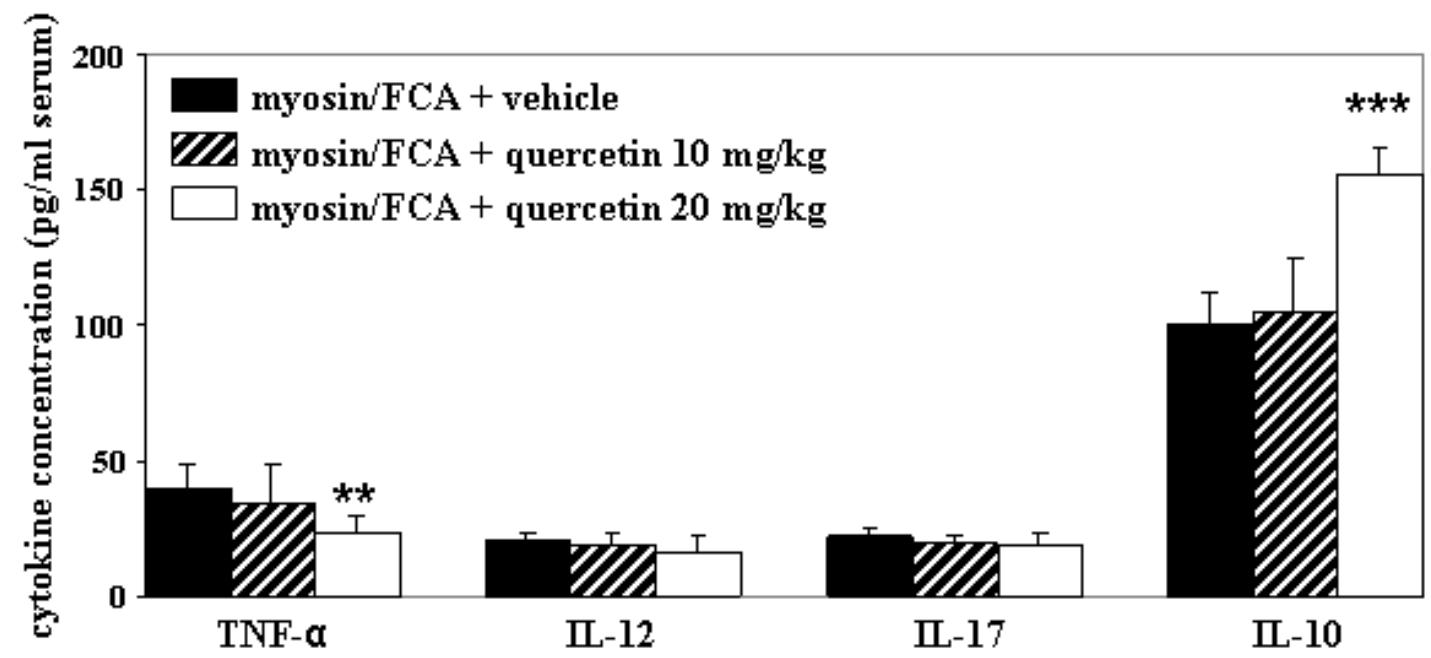

Figure 2. The effect of quercetin on TNF- $\alpha$, IL-12, IL-17 and IL-10 serum levels. Animals immunized with myosin/FCA (EAM rats) were treated with vehicle or quercetin $(10$ and $20 \mathrm{mg} / \mathrm{kg}$ ) from days 0 to 21 after induction of myocarditis. On day 21 serum levels of TNF- $\alpha$,IL-12, IL-17 and IL-10 were measured using ELISA. Results are expressed as mean values \pm SD. For statistical analysis each group was compared to vehicle-treated rats by MannWhitney U-test. ${ }^{* *} \mathrm{p}<0.01,{ }^{* * *} \mathrm{p}<0.001$.

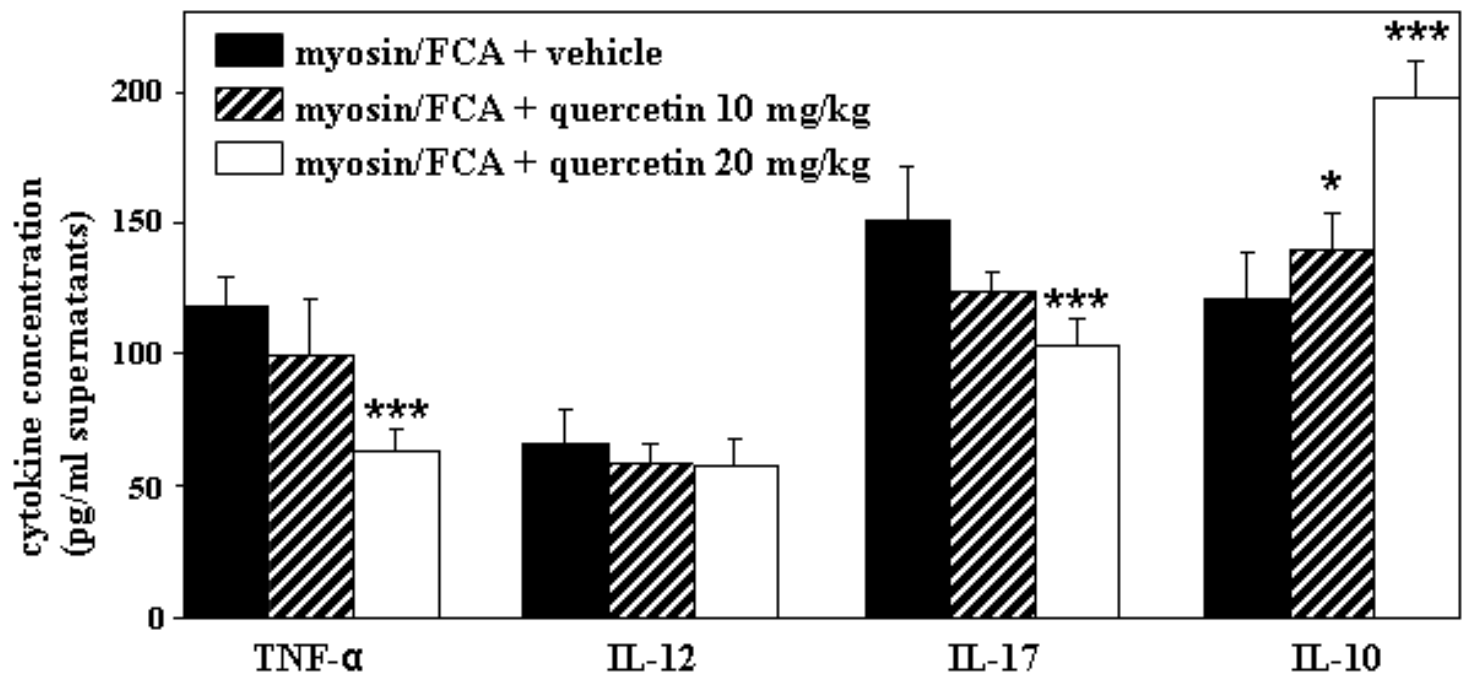

Figure 3. The effect of quercetin on production of TNF- $\alpha$, IL-12, IL-17 and IL-10 in culture supernatants of ConAprimed lymph node cells. Lymph node cells isolated from vehicle- and quercetin-treated EAM rats on day 21 after induction of disease were grown in vitro for $48 \mathrm{~h}$ with Con-A $(2.5 \mu \mathrm{g} / \mathrm{ml})$ and the production of TNF- $\alpha$, IL-12, IL-17 and IL-10 was subsequently measured in cell culture supernatants by ELISA. Data are expressed as mean values \pm SD, and are significantly different from those of the vehicle-treated EAM rats. ${ }^{*} \mathrm{p}<0.05,{ }^{* * *} \mathrm{p}<0.001$

\section{DISCUSSION}

Treatment of acute myocarditis in humans remains a major clinical problem (32). Because evidence has accumulated that autoimmune mechanisms play a pivotal role in myocarditis and
DCM, immunomodulatory therapy has attracted a great deal of attention. The current study has aimed to investigate the effects of quercetin, preselected from its ability to inhibit TNF- $\alpha$ production in vitro, on experimental autoimmune myocarditis in rats. In animal models, quercetin 
was found to be effective in $\mathrm{T}$ cell-mediated autoimmune diseases such as adjuvant arthritis and experimental autoimmune encephalomyelitis $(19,23)$.

We found that daily administration of $20 \mathrm{mg} /$ $\mathrm{kg}$ bw of quercetin for 3 weeks ameliorated autoimmune myocarditis significantly. In quercetin-treated group markers reflecting the severity of myocarditis including the $\mathrm{Hw} / \mathrm{Bw}$ ratio, macroscopic and microscopic scores were lower than in the vehicle-treated group.

The pathogenic mechanism of the EAM model involves three sequential processes. In the first step autoreactive $\mathrm{T}$ cells are activated and expanded by a fragment of cardiac myosin. The second step is recruitment of activated $T$ cells to the target organ, and the third step appears to be effector-target interaction. Cells causing inflammation consist primarily of macrophages and CD4 positive $\mathrm{T}$ cells. During the inflammatory phase of EAM, Th1 cytokines (IL$2, \mathrm{IFN}-\gamma$ ) and proinflammatory cytokines (IL-1 $\beta$, TNF- $\alpha$ ) are produced. The participation of TNF- $\alpha$ in the pathogenesis of EAM has been clearly demonstrated. Administration of TNF- $\alpha$ results in exacerbation of myocardial inflammation (33), while the functional blockade or suppression of TNF- $\alpha$ production results in attenuation of cardiac inflammation $(34,35)$. The concentration of TNF- $\alpha$ is elevated in patients with myocarditis (36). Our study showed that both serum levels and in vitro production of TNF- $\alpha$ were significantly decreased in EAM animals treated with quercetin. These results support the possibility that quercetin ameliorates EAM by inhibiting the production of TNF- $\alpha$ Previous findings that quercetin significantly inhibits TNF- $\alpha$ production by human peripheral blood mononuclear cells and murine

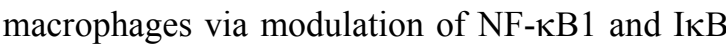
$(24,25)$ are in agreement with above assumption.

We further assessed the influence of quercetin treatment on IL-10 production in EAM rats. IL-10 is produced by Th2 cells and monocytes/macrophages, and is an antagonist of Th1 cytokines. In EAM hearts, IL-10 was mainly detected in non-cardiomyocytic non-inflammatory cells (mainly fibroblasts, smooth muscle cells, and endothelial cells) (37) and IL-10 targeting cells, which expressed IL-10 receptors, were mainly $\mathrm{T}$ cells expressing $\alpha \beta \mathrm{T}$ cell antigen receptors $(\alpha \beta+\mathrm{T}$ cells $)$ and $\mathrm{CD} 11 \mathrm{~b}+$ cells (macrophages/dendritic cells/ granulocytes) (37, 38). Several studies have demonstrated the therapeutic effect of IL-10 in myocarditis.
Watanabe et al. showed that gene transfer of IL10 into muscle by electroporation in vivo was effective for the treatment of EAM (39). Administration of IL-10 attenuated myocardial inflammation and inhibited inducible $\mathrm{NO}$ synthase and the secretion of proinflammatory cytokines such as TNF- $\alpha$, IFN- $\gamma$, IL-2 and IL-12 $(40,41)$. Here we showed that the level of IL-10 in serum and also in supernatants of LNC was significantly higher in EAM rats treated with quercetin compared with vehicle-treated EAM rats. These results indicate that ameliorating effects of quercetin on EAM could be ascribed, at least in part, to up-regulation of IL-10 production.

Recent data suggest that proinflammatory cytokine IL-17 plays an important role in pathogenesis of EAM $(10,13,42)$. In mice, EAM development critically depends on the IL-23STAT4 axis that promotes the expansion of pathogenic IL-17 - producing Th17 subset (9). Adoptive transfer of myosin-specific CD4+ Th17 cells induced autoimmune myocarditis in healthy mice (43) and treatment with antibodies to block IL-17 ameliorated disease severity in mice with ongoing EAM (10). Chang and colleagues proved the pathogenic role of IL-17 in the development of rat EAM (14). In the present study, we found that production of IL-17 by LNC was reduced in EAM rats treated with quercetin compared with vehicle-treated animals. These data indicate that quercetin ameliorated EAM, not only through the inhibition of production of TNF- $\alpha$, but also through suppression of IL-17. There was no significant difference in serum level of IL-17 between quercetin- and vehicle-treated EAM animals. It is possible that immunomodulatory effect of quercetin on IL-17 production can only be detected in vitro or at the level of IL-17 mRNA in the myocardium.

IL-12, produced by a variety of antigenpresenting cells, including monocytes, macrophages, and dendritic cells, has been suggested to be involved in development of EAM as IL-12 (p40) and IL-12 receptor $\beta 1$ knockouts are protected from disease $(9,44)$. However, more recently it became clear that the heterodimers IL$12(\mathrm{p} 40 / 35)$ and IL-23 (p40/p19) share the p40 subunit and the $\beta 1$ chain of their receptor and that IL-23, not IL-12 is essential for inflammatory heart disease (10). We demonstrated that quercetin did not influence the production of IL12 since neither serum level, nor production of this cytokine by LNC differed between quercetinand vehicle-treated EAM animals. These results suggest that ameliorating effect of quercetin in 
EAM was not associated with inhibition of IL-12 secretion. In line with our findings are previously reported data that IL-12 is not critical for EAM development (10).

This study has some limitations. During our experiment, the drug treatment started at the same time with immunization of rats with the conclusion that quercetin reduced the severity of autoimmune myocarditis, while the onset process of the disease is usually advanced before administration of any drug to humans. We can not therefore extrapolate directly our results to humans and further investigations are needed before clinical use.

In conclusion, from our data, quercetin reduced the severity of EAM and the mechanism of amelioration of the disease by this flavonoid could be ascribed to suppression of proinflammatory cytokines such as TNF- $\alpha$ and IL-17 and up-regulation of IL-10. Therefore, it is anticipated that quercetin may be beneficial in autoimmune myocarditis.

\section{ACKNOWLEDGMENTS}

We thank Ms. Gordana Zdunjić (Institute for Medicinal Plant Research, 'Dr Josif Pancic') for kindly providing the quercetin.

\section{REFERENCES}

1. Mason JW, O'Connell JB, Herskowitz A, Rose NR, McManus BM, Billingham ME, Moon TE. A clinical trial of immunosuppressive therapy for myocarditis. The Myocarditis Treatment Trial Investigators, N Engl J Med 1995; 333(5):269275.

2. D'Ambrosio A, Patti G, Manzoli A, Sinagra G, Di Lenarda A, Silvestri F, Di Sciascio G. The fate of acute myocarditis between spontaneous improvement and evolution to dilated cardiomyopathy: a review. Heart 2001; 85(5):499504.

3. Kim KS , Hufnagel G, Chapman NM, Tracy S .The group B coxsackieviruses and myocarditis. Rev Med Virol 2001; 11(6):355-368.

4. Caforio AL, Mahon NJ, Tona F, McKenna WJ. Circulating cardiac autoantibodies in dilated cardiomyopathy and myocarditis: pathogenetic and clinical significance. Eur J Heart Fail 2002; 4(4):411-417.

5. Rose NR. Myocarditis: infection versus autoimmunity. J Clin Immunol 2009; 29:730-737.

6. Kodama M, Hanawa H, Saeki M, Hosono H, Inomata T, Suzuki K, Shibata A. Rat dilated cardiomyopathy after autoimmune giant cell myocarditis. Circ Res 1994; 75(2):278-284.
7. Dimitrijević M, Milenković M, Milosavljević P, Stojić-Vukanić Z, Čolić M, Bartlett R. Beneficial effects of leflunomide on cardiac myosin-induced experimental autoimmune myocarditis in rats. Int $\mathrm{J}$ Immunotherapy 1998; XIV(1):9-21.

8. Okura $\mathrm{Y}$, Yamamoto $\mathrm{T}$, Goto $\mathrm{S}$, Inomata $\mathrm{T}$, Hirono S, Hanawa H, Feng L, Wilson CB, Kihara I, Izumi T, Shibata A, Aizawa Y, Seki S, Abo T. Characterization of cytokine and iNOS mRNA expression in situ during the corse of experimental autoimmune myocarditis in rats. $\mathrm{J}$ Moll Cell Cardiol 1997; 29:491-502.

9. Afanasyeva M, Wang Y, Kaya Z, Stafford EA, Dohmen KM, Sadighi Akha AA, Rose NR. Interleukin-12 receptor/STAT4 signaling is required for the development of autoimmune myocarditis in mice by an interferon-gammaindependent pathway. Circulation 2001; 104(25):3145-3151.

10. Sonderegger I, Röhn TA, Kurrer MO, Iezzi G, Zou Y, Kastelein RA, Bachmann MF, Kopf M. Neutralization of IL-17 by active vaccination inhibits IL-23-dependent autoimmune myocarditis. Eur J Immunol 2006; 36(11):28492856.

11. McGeachy MJ, Cua DJ. Th17 cell differentiation: the long and winding road. Immunity 2008; 28(4):445-453.

12. Komiyama Y, Nakae S, Matsuki T, Nambu A, Ishigame H, Kakuta S, Sudo K, Iwakura Y. IL-17 plays an important role in the development of experimental autoimmune encephalomyelitis. J Immunol 2006; 177(1):566-573.

13. Rangachari M, Mauermann N, Marty RR, Dirnhofer S, Kurrer MO, Komnenovic V, Penninger JM, Eriksson U. T-bet negatively regulates autoimmune myocarditis by suppressing local production of interleukin 17. J Exp Med 2006; 203(8):2009-2019.

14. Chang H, Hanawa H, Yoshida T, Hayashi M, Liu H, Ding L, Otaki K, Hao K, Yoshida K, Kato K, Toba K, Kodama M, Maruyama H, Miyazaki J, Aizawa Y. Alteration of IL-17 related protein expressions in experimental autoimmune myocarditis and inhibition of IL-17 by IL-10-Ig fusion gene transfer. Circ J 2008; 72(5):813-819.

15. Hollman PC, Katan MB. Health effects and bioavailability of dietary flavonols. Free Radic Res 1999; 31:75-80.

16. Ross JA, Kasum CM. Dietary flavonoids: bioavailability, metabolic effects, and safety. Annu Rev Nutr 2002; 22:19-34.

17. Knekt $P$, Kumpulainen J, Järvinen R, Rissanen $H$, Heliövaara M, Reunanen A, Hakulinen T, Aromaa A. Flavonoid intake and risk of chronic diseases. Am J Clin Nutr 2002; 76(3):560-568.

18. Rice-Evans C, Spencer JP, Schroeter H, Rechner AR. Bioavailability of flavonoids and potential bioactive forms in vivo. Drug Metabol Drug Interact 2000; 17:291-310. 
19. Guardia T, Rotelli AE, Juarez AO, Pelzer LE. Anti-inflammatory properties of plant flavonoids. Effects of rutin, quercetin and hesperidin on adjuvant arthritis in rat. Farmaco 2001; 56(9):683687.

20. Rotelli AE, Guardia T, Juárez AO, de la Rocha NE, Pelzer LE. Comparative study of flavonoids in experimental models of inflammation. Pharmacol Res 2003; 48(6):601-606.

21. Camuesco D, Comalada M, Rodríguez-Cabezas ME, Nieto A, Lorente MD, Concha A, Zarzuelo A, Gálvez J.The intestinal anti-inflammatory effect of quercitrin is associated with an inhibition in iNOS expression. $\mathrm{Br} \mathrm{J}$ Pharmacol 2004; 143(7):908-918.

22. Verbeek R, van Tol EA, van Noort JM. Oral flavonoids delay recovery from experimental autoimmune encephalomyelitis in SJL mice. Biochem Pharmacol 2005; 70(2):220-228.

23. Hendriks JJ, Alblas J, van der Pol SM, van Tol EA, Dijkstra CD, de Vries HE. Flavonoids influence monocytic GTPase activity and are protective in experimental allergic encephalitis. J Exp Med 2004; 200(12):1667-1672.

24. Cho SY, Park SJ, Kwon MJ, Jeong TS, Bok SH, Choi WY, Jeong WI, Ryu SY, Do SH, Lee CS, Song JC, Jeong KS. Quercetin suppresses proinflammatory cytokines production through MAP kinases and NF-kappaB pathway in lipopolysaccharide-stimulated macrophage. Mol Cell Biochem 2003; 243(1-2):153-160.

25. Nair MP, Mahajan S, Reynolds JL, Aalinkeel R, Nair H, Schwartz SA, Kandaswami C. The flavonoid quercetin inhibits proinflammatory cytokine (tumor necrosis factor alpha) gene expression in normal peripheral blood mononuclear cells via modulation of the NF-kappa beta system. Clin Vaccine Immunol 2006; 13(3):319-328.

26. Xagorari A, Papapetropoulos A, Mauromatis A, Economou M, Fotsis T, Roussos C Luteolin inhibits an endotoxin-stimulated phosphorylation cascade and proinflammatory cytokine production in macrophages. J Pharmacol Exp Ther 2001; 296(1):181-187.

27. Kodama M, Matsumoto Y, Fujiwara M, Masani F, Izumi T, Shibata A. A novel experimental model of giant cell myocarditis induced in rats by immunization with cardiac myosin fraction. Clin Immunol Immunopathol 1990; 57:250-262.

28. Milenković M, Vučićević D, Milosavljević P, Arsenović-Ranin N, Stojić-Vukanić Z, Čolić M. Suppression of experimental autoimmune myocarditis by sodium fusidate (fusidin). Pharmacol Res 2005; 52:491-496.

29. Dunnick JK, Hailey JR. Toxicity and carcinogenicity studies of quercetin, a natural component of foods. Toxicol Sci 1992; 19(3):423431.

30. Hubbard GP, Wolffram S, Lovegrove JA, Gibbins JM Ingestion of quercetin inhibits platelet aggregation and essential components of the collagen-stimulated platelet activation pathway in humans. J Thromb Haemost 2004; 2(12):21382145 .

31. Di Marco R, Khademi M, Wallstrom E, Muhallab S, Nicoletti F, Olsson T. Amelioration of experimental allergic neuritis by sodium fusidate (fusidin): suppression of IFN-gamma and TNFalpha and enhancement of IL-10. J Autoimmun 1999; 13(2):187-195.

32. Feldman AM, McNamara D. Myocarditis. N Engl J Med 2000; 343(19):1388-1398.

33. Lane JR, Neumann DA, Lafond-Walker A, Herskowitz A, Rose NR. Interleukin 1 or tumor necrosis factor can promote Coxsackie virusinduced myocarditis in resistant B10.A mice. J Exp Med 1992; 175:1123-1129.

34. Smith SC, Allen PM. Neutralization of endogenous tumor necrosis factor ameliorates the severity of myosin-induced myocarditis. Circ Res 1992; 70(4):856-863.

35. Bachmaier K, Pummerer C, Kozieradzki I, Pfeffer $\mathrm{K}$, Mak TW, Neu N, Penninger JM. Lowmolecular-weight tumor necrosis factor receptor p55 controls induction of autoimmune heart disease. Circulation 1997; 95(3):655-661.

36. Hegewisch S, Weh HJ, Hossfeld DK. TNFinduced cardiomyopathy. Lancet 1990; 335(8684):294-305.

37. Yoshida T, Hanawa $H$, Toba $K$, Watanabe $H$, Watanabe R, Yoshida K, Abe S, Kato K, Kodama M, Aizawa Y. Expression of immunological molecules by cardiomyocytes and inflammatory and interstitial cells in rat autoimmune myocarditis. Cardiovasc Res 2005; 68(2):278-288.

38. Chang H, Hanawa H, Liu H, Yoshida T, Hayashi M, Watanabe R, Abe S, Toba K, Yoshida K, Elnaggar R, Minagawa S, Okura Y, Kato K, Kodama M, Maruyama H, Miyazaki J, Aizawa Y. Hydrodynamic-based delivery of an interleukin22-Ig fusion gene ameliorates experimental autoimmune myocarditis in rats. J Immunol 2006; 177(6):3635-3643.

39. Watanabe K, Nakazawa M, Fuse K, Hanawa H, Kodama M, Aizawa Y, Ohnuki T, Gejyo F, Maruyama H, Miyazaki J. Protection against autoimmune myocarditis by gene transfer of interleukin-10 by electroporation. Circulation 2001; 104(10):1098-1100.

40. Nishio R, Matsumori A, Shioi T, Ishida H, Sasayama S.Treatment of experimental viral myocarditis with interleukin-10. Circulation 1999; 100(10):1102-1108.

41. Yang S, Li W, Liu W, Gao C, Zhou B, Li S, Li Y, Kong Y. IL-10 gene modified dendritic cells induced antigen-specific tolerance in experimental autoimmune myocarditis. Clin Immunol 2006; 121(1):63-73.

42. Mathur AN, Chang HC, Zisoulis DG, Stritesky GL, Yu Q, O'Malley JT, Kapur R, Levy DE, Kansas GS, Kaplan MH. Stat3 and Stat4 direct 
development of IL-17-secreting Th cells. J Immunol 2007; 178(8):4901-4907.

43. Valaperti A, Marty RR, Kania G, Germano D, Mauermann N, Dirnhofer S, Leimenstoll B, Blyszczuk P, Dong C, Mueller C, Hunziker L, Eriksson U. CD11b+ monocytes abrogate Th17 CD4+ T cell-mediated experimental autoimmune myocarditis. J Immunol 2008; 180(4):2686-2695.
44. Eriksson U, Kurrer MO, Sebald W, Brombacher F, Kopf M. Dual role of the IL-12/IFN-gamma axis in the development of autoimmune myocarditis: induction by IL-12 and protection by IFN-gamma. J Immunol 2001; 167(9):5464-5469. 